\title{
Qualification of tropical fruit-derived Lactobacillus plantarum strains as potential probiotics acting on blood glucose and total cholesterol levels in Wistar rats
}

\author{
Whyara Karoline Almeida da Costa ${ }^{\mathrm{a}}$, Larissa Ramalho Brandão ${ }^{\mathrm{a}}$, Maria Elena Martino ${ }^{\mathrm{b}}$, \\ Estefânia Fernandes Garciac ${ }^{c}$, Adriano Francisco Alves ${ }^{\mathrm{d}}$, Evandro Leite de Souza ${ }^{\mathrm{c}}$, \\ Jailane de Souza Aquino ${ }^{\mathrm{e}}$, Maria Saarela ${ }^{\mathrm{f}}$, François Leulier ${ }^{\mathrm{b}}$, Hubert Vidal ${ }^{\mathrm{g}}$, Marciane Magnani ${ }^{\mathrm{a}, *}$

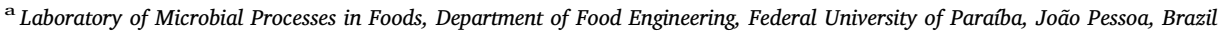 \\ ${ }^{\mathrm{b}}$ Institute of Functional Genomics of Lyon (IGFL), Université de Lyon, Ecole Normale supérieure de Lyon, CNRS UMR 5242, Université Claude Bernard Lyon-I, Lyon, \\ France \\ ${ }^{c}$ Laboratory of Food Microbiology, Department of Nutrition, Health Sciences Center, Federal University of Paraíba, João Pessoa, Paraíba, Brazil \\ d Institute of Biological Sciences, Department of Pathology, Federal University of Minas Gerais, Minas Gerais, Brazil \\ ${ }^{\mathrm{e}}$ Laboratory of Experimental Nutrition, Department of Nutrition, Federal University of Paraíba, João Pessoa, Paraíba, Brazil \\ ${ }^{\mathrm{f}}$ VTT Technical Research Centre of Finland, Espoo, Finland \\ ${ }^{g}$ CarMeN Laboratory, Université de Lyon, INSERM, INRA, INSA-Lyon, University Claude Bernard Lyon 1, Lyon, France
}

A R T I C L E I N F O

\section{Keywords:}

Lactobacillus plantarum

Grow promotion

Safety

Probiotics

Metabolic modulation

\begin{abstract}
A B S T R A C T
Tropical fruit and their industrial processing byproducts have been considered sources of probiotic Lactobacillus. Sixteen tropical fruit-derived Lactobacillus strains were assessed for growth-promoting effects using a hostcommensal nutrient scarcity model with Drosophila melanogaster (Dm). Two Lactobacillus strains (L. plantarum 49 and L. plantarum 201) presenting the most significant effects $(\mathrm{p} \leq .005)$ on $D m$ growth were selected and evaluated for their safety and beneficial effects in adult male Wistar rats during 28 days of administration of 9 $\log$ CFU/day, followed by 14 days of wash-out. Daily administration of L. plantarum 49 and L. plantarum 201 did not affect $(\mathrm{p}>.05)$ food intake or morphometric parameters. Both strains were associated with reduction ( $\mathrm{p} \leq .05$ ) in blood glucose levels after 28 days of administration and after wash-out period; glucose levels remained reduced only in the group that received $L$. plantarum 49 . Both strains were able to reduce $(\mathrm{p} \leq .05)$ total cholesterol levels after 14 days of administration; after the wash-out period these levels remained reduced only in the group that received L. plantarum 201. L. plantarum 49 and L. plantarum 201 were detected in the intestine and did not cause alteration or translocate to spleen, kidneys or liver during the experimental or wash-out period. These results indicate that $L$. plantarum 49 and $L$. plantarum 201 present potential for use as probiotics with intrinsic abilities to modulate biochemical parameters of interest for the management of metabolic diseases.
\end{abstract}

\section{Introduction}

Probiotics are live microorganisms, which exert a positive health benefit on the host when ingested in an adequate amount $(\mathrm{FAO} / \mathrm{WHO}$, 2006). Tropical fruit and their industrial processing byproducts have been considered sources of Lactobacillus with the required features for a probiotic because this genus represents great part of the autochthonous raw fruit microbiota (Garcia et al., 2016). Some physicochemical parameters of fruit or fruit-by-products, such as acidity and presence of competitive microbiota, may resemble traits of the human gastrointestinal tract (Vitali et al., 2012). Previous studies have suggested that previous adaptation to these conditions might help fruitderived Lactobacillus to survive in the human gastrointestinal tract (Albuquerque et al., 2017; Vitali et al., 2012).

In addition to the experimental evaluation of beneficial effects, the safety of use is a critical factor to establish the probiotic potential of new strains (Park et al., 2017; Shanahan, 2012). Primarily, the possible translocation of bacteria to extra intestinal organs should be assessed using in vivo models, which are also relevant to select promising strains with prophylactic or therapeutic effects (Daniel et al., 2006; Sanders

\footnotetext{
* Corresponding author at: Laboratory of Microbial Processes in Foods, Department of Food Engineering, Technology Center, Federal University of Paraíba, Campus I, 58051-900 João Pessoa, Brazil.

E-mail addresses: magnani2@gmail.com.br, magnani2@pq.cnpq.br (M. Magnani).
} 
et al., 2010). Furthermore, the identification of a new probiotic strain when administrated to animal models is important to avoid to be confounded with strains of the same species in host microbiota (Kechagia et al., 2013; Park et al., 2017).

Recently, a scarcity nutrient model using Drosophila melanogaster flies has been proposed for screening of new beneficial strains for growth-promoting effects (Schwarzer et al., 2016; Storelli et al., 2011). Once $D$. melanogaster larval growth is fully dependent on food richness environment, poor-nutrient environment severely affects both its systemic growth and maturation rate and consequently influences the timing of adult emergence. Under nutrient shortage, D. melanogaster microbiota is necessary for optimal larval development (Storelli et al., 2011). The use of monoxenic model (one microbe-one host) has been considered effective to reveal if a such strain exerts promoting effects on D. melanogaster growth (Erkosar et al., 2015). Since the growth promoting ability of lactobacilli in $D$. melanogaster can be translated to mice (Schwarzer et al., 2016), the model may represent a fast and straight-forward screening method for selection of beneficial strains.

Among the Lactobacillus species assessed for probiotic features, $L$. plantarum has been considered as a highly versatile species able to promote distinct health effects (Karasu, Simsek, \& Con, 2010; Siezen \& Vlieg, 2011). Earlier studies have reported that specific strains of $L$. plantarum can inhibit obesity development by reducing mesenteric adipose tissue (Park et al., 2017) and favoring lipid metabolism in a diet-induced obesity murine model (Kim, Hong, Choi, \& Kim, 2014). Anti-diabetic and hypoglycemic effects have also been reported for strains of L. plantarum isolated from distinct sources (Li et al., 2016a, 2016b). Previous studies have described features that characterize tropical fruit-derived Lactobacillus strains as potential probiotics using in vitro approaches (Albuquerque et al., 2017; Costa et al., 2018; Garcia et al., 2016). However, the safety and health-promoting effects of such strains remains unknown.

This study evaluated the growth-promoting effects of sixteen fruitderived potentially probiotic Lactobacillus strains using the host-commensal $D$. melanogaster nutrient scarcity model. The strains $L$. plantarum 49 and L. plantarum 201, which presented the most significant growthpromoting effects, were further evaluated for their safety and effects on murinometric, biochemical and histopathological parameters in healthy male Wistar rats.

\section{Materials and methods}

\subsection{Tested strains and inoculum preparation}

Sixteen strains comprising different Lactobacillus species previously isolated from the pulp of Mangifera indica L., or from industrial fruit pulp processing byproducts of Malphigia glabra L., M. indica L., Annona muricata L. and Fragaria ananassa L. that previously presented characteristics compatible with probiotic use were included in this study (Table 1) (Garcia et al., 2016). The strains Lactobacillus plantarum WJL and L. plantarum NIZO2877 were used as controls in a growth promoting screen assay in situation of nutrient scarcity in Drosophila melanogaster (Schwarzer et al., 2016; Storelli et al., 2011). Stock cultures of Lactobacillus strains were maintained in cryovials at $-80^{\circ} \mathrm{C}$ in de Man, Rogosa and Sharpe (MRS) broth (HiMedia, Mumbai, India) containing glycerol $20 \%(\mathrm{v} / \mathrm{v})$.

Each inoculum was obtained by preparing suspensions in sterile saline solution from overnight cultures grown on MRS broth (HiMedia, Mumbai, India) and incubated anaerobically (Anaerobic System Anaerogen, Oxoid Ltda., Wade Road, UK) at $37^{\circ} \mathrm{C}$. Cells were harvested by centrifugation $\left(4500 \times g, 15 \mathrm{~min}, 4^{\circ} \mathrm{C}\right)$, washed twice with sterile saline solution, re-suspended and homogenized using a vortex (30 s) in sterile saline solution to obtain standard cell suspensions with optical density (OD) reading at $660 \mathrm{~nm}\left(\mathrm{OD}_{660}\right)$ of 1.0 , which provided viable counts of approximately $9 \log \mathrm{CFU} / \mathrm{mL}$.
Table 1

Lactobacillus strains included in the study and their respective source (fruit or byproduct of pulp processing) of isolation.

\begin{tabular}{ll}
\hline Cepas teste & Fonte de isolamento \\
\hline Lactobacillus plantarum WJL* & $\begin{array}{l}\text { Drosophilla melanogaster } \\
\text { Lactobacillus plantarum Nizo 21* }\end{array}$ \\
Lactobacillus plantarum 40 & Byproduct of guava (Psidium guajava L.) \\
Lactobacillus plantarum 49 & Pulp of barbados cherry (Malphigia glabra L.) \\
Lactobacillus plantarum 53 & Byproduct of barbados cherry (M. glabra L.) \\
Lactobacillus plantarum 54 & Byproduct of barbados cherry $(M$. glabra L.) \\
Lactobacillus brevis 59 & Byproduct of barbados cherry $(M$. glabra L.) \\
Lactobacillus paracasei 62 & Byproduct of barbados cherry $(M$. glabra L.) \\
Lactobacillus paracasei 106 & Byproduct of soursop (Annona muricata L.) \\
Lactobacillus paracasei 108 & Byproduct of soursop (A. muricata L.) \\
Lactobacillus fermentum 111 & Byproduct of soursop (A. muricata L.) \\
Lactobacillus fermentum 129 & Byproduct of mango (Mangifera indica L.) \\
Lactobacillus fermentum 139 & Byproduct of mango (M. indica L.) \\
Lactobacillus fermentum 141 & Byproduct of mango (M. indica L.) \\
Lactobacillus plantarum 198 & Byproduct of mango (M. indica L.) \\
Lactobacillus plantarum 201 & Byproduct of mango $(M$. indica L.) \\
Lactobacillus fermentum 210 & Pulp of mango (M. indica L.) \\
Lactobacillus fermentum 296 & Byproduct of strawberry (Fragaria ananassa \\
& L.)
\end{tabular}

\subsection{Screening of Lactobacillus strains using a nutrient scarcity model}

To screen the Lactobacillus strains based on their growth promoting effects, a biological host-commensal nutrient scarcity model with Drosophila melanogaster mono colonized flies was used following previously described procedures (Storelli et al., 2011). D. melanogaster stocks were kept at $25^{\circ} \mathrm{C}$ using a rich diet comprising yeast extract and corn meal medium. The rich diet comprised corn-meal flour (Westhove, Farigel maize H1; $80 \mathrm{~g} / \mathrm{L}$ ), inactivated dried yeast (Springaline; $50 \mathrm{~g} / \mathrm{L}$ ) and agar (VWR; $8.2 \mathrm{~g} / \mathrm{L}$ ) cooked for $10 \mathrm{~min}$ in boiling water; methylparaben sodium salt (Merck; $5.2 \mathrm{~g} / \mathrm{L}$ ) and propionic acid (99\% v/v Carlo Erba; $4 \mathrm{~mL} / \mathrm{L}$ ) were added when the food formulation had cooled down. The diet used for nutrient scarcity (poor diet) was obtained by reducing the amount of inactivated yeast to $6 \mathrm{~g} / \mathrm{L}$. The diets were prepared weekly to avoid desiccation. Conventionally reared (CR) $D$. melanogaster stocks carry a conventional microbiota, which was removed in germ-free (GF) D. melanogaster individuals by bleaching and cultivating embryos on autoclaved conventional medium. GF D. melanogaster stocks were maintained on a rich diet supplemented with a cocktail of four antibiotics (ampicillin/kanamycin/tetracyclin at $50 \mu \mathrm{g} /$ $\mathrm{mL}$ final each and erythromycin at $10 \mu \mathrm{g} / \mathrm{mL}$ final). GF females laid GF embryos, which were grown on appropriate culture medium (rich or poor diet). Bacterial suspensions of test Lactobacillus ( $150 \mathrm{~mL}, 10^{7} \mathrm{CFU}$ / $\mathrm{mL}$ ) were then added directly on the embryos and the food after the egg-laying period. L. plantarum WJL and L. plantarum NIZO2877 were used as control strains and analyzed as previously described (Schwarzer et al., 2016; Storelli et al., 2011). Emerging larvae were allowed to develop for seven days on the inoculated media. Larvae were frozen and mounted on a slide in $80 \%$ glycerol in PBS. Pictures were taken on a black background using a ProgResC5 CCD camera (JenOptik) mounted on a stereomicroscope. The body length of each larva was measured using ImageJ (2015). The assays were performed in at least three biological replicates, including at least 30 individuals each.

\subsubsection{Genome sequencing and design of strain-specific primers for growth- promoting L. plantarum strains}

The strains $L$. plantarum 49 and $L$. plantarum 201, which were selected considering their performance in scarcity model assay, were submitted to whole genome sequencing to design primers that allow their molecular identification in samples collected during the experimental evaluation in rats. Bacterial genomic DNA was extracted from cultures grown to stationary phase in MRS broth using the UltraClean Microbial DNA isolation kit (Mo Bio, Qiagen, USA). The sequencing was 
performed following the procedures described by Kim, Park, Lee, and Lee (2013). Genomic libraries were prepared following Ion Xpress Plus gDNA Fragment Library construction protocol for $400 \mathrm{bp}$ reads. The strains were sequenced using the Ion Torrent PGM platform. The DNA library construction and sequencing were performed on the IGFL sequencing platform (Lyon, France). Gap closing and resequencing of low-quality regions were conducted by Sanger sequencing to reach high-quality finished genome sequence. Gaps were closed by designing primer pairs between contigs using the Primer3 software (Untergrasser et al., 2012). The endpoint PCRs were conducted on a Veriti Applied Biosystems thermocycler (Life Technologies, Carlsbad, CA). Functional annotations of the predicted genes were performed using the RAST Server (Aziz et al., 2008). The genomic regions specific to L. plantarum 49 and 201 strains have been manually identified through alignment of each strain of interest with all the L. plantarum strain genomes available in NCBI at the time of the analysis (August 2015). The strain-specific primer pairs were designed using Geneious 7 (Kearse et al., 2012).

PCR amplifications were performed in a final volume of $20 \mu \mathrm{L}$ and the optimized conditions for the strain-specific primers were: $95^{\circ} \mathrm{C}$ for $2 \mathrm{~min}$, followed by 35 cycles of denaturation $\left(95^{\circ} \mathrm{C}, 30 \mathrm{~s}\right)$, annealing $\left(58^{\circ} \mathrm{C}, 30 \mathrm{~s}\right.$ and $\left.72{ }^{\circ} \mathrm{C}, 1 \mathrm{~min} 30 \mathrm{~s}\right)$ and elongation $\left(72^{\circ} \mathrm{C}, 7 \mathrm{~min}\right)$. The following $L$. plantarum strains have been used as negative controls of amplification in both PCRs: L. plantarum NIZO2877, L. plantarum WJL, L. plantarum WCFS1 and L. plantarum NC8. After electrophoresis in agarose gel $1 \%$, the gels were treated with ethidium bromide, visualized under ultraviolet light (UV) and documented.

\subsection{Evaluation of safety aspects and beneficial effects of Lactobacillus using Wistar rats}

Forty-eight male Wistar rats at 21 days were used in the study. All experiments were previously approved by the Animal Research Ethics Committee (Federal University of Pernambuco, Recife, Brazil; protocol number 23076.024378/2015-13 CEUA/UFPE). Experimental procedures were performed in accordance with revised guide for the care and use of laboratory animals (Bayne, 1996).

Rats were kept in individual cages $\left(22 \pm 1{ }^{\circ} \mathrm{C} ; 12 \mathrm{~h}\right.$ photoperiod; $50-55 \%$ relative humidity) with food (AIN $93 \mathrm{M}$ diet) and water provided ad libitum (Reeves, Nielsen, \& Fahey, 1993) and randomly distributed into three groups of 16 animals as follow: group Lp49, which received $9 \log \mathrm{CFU} / \mathrm{mL}$ of strain L. plantarum 49; group Lp201, which received $9 \log \mathrm{CFU} / \mathrm{mL}$ of strain L. plantarum; and control group, which received PBS daily by orogastric gavage during four weeks. Before the administration (baseline values), after 14 and 28 days of administration and during the wash-out period (14 days after the end of the administration of lactobacilli strains or PBS), four rats per group were fasted for $12 \mathrm{~h}$ and anesthetized by intraperitoneal injection of $1 \mathrm{~mL}$ of ketamine hydrochloride $(75 \mathrm{mg})$ and $1 \mathrm{~mL}$ of xylazine hydrochloride $(5 \mathrm{mg})$ per $\mathrm{kg}$ body weight. At each evaluation point, feces were collected and the murinometric parameters were measured. Blood samples were collected by cardiac puncture in the left ventricle and after the euthanasia via aortic transection, organs (intestine, kidneys, spleen and liver) were removed, weighted, subdivided and randomly distributed for microbiological and histopathological analysis (Batista et al., 2018).

\subsubsection{Determination of murinometric parameters}

Using a tape measure, the abdominal circumference (AC) immediately preceding the front leg, the thoracic circumference (TCi) immediately behind the foreleg and the body length from the nose to the base of the tail were measured. Body weight was obtained and body mass index (BMI) was calculated by dividing body weight (g) by body length squared $\left(\mathrm{cm}^{2}\right)$ (Novelli et al., 2007). The Lee index (LI) was calculated by dividing the cube root of body weight $(\mathrm{g})$ by length $(\mathrm{cm})$. Food intake was recorded daily (Lien et al., 2001).

\subsubsection{Serum analysis and lipid profile}

Four milliliters of blood was collected via direct cardiac puncture and centrifuged $\left(807 \times g, 10 \mathrm{~min}, 4^{\circ} \mathrm{C}\right)$ from anesthetized animals. The serum levels of glucose were measured using the Glucose PAP Liquiform kit (Labtest ${ }^{\circledast}$, Minas Gerais, Brazil). The serum levels of aspartate transaminase (AST) and alanine transaminase (ALT) were analyzed using the AST and ALT kits (Bioclin ${ }^{\circledR}$, Minas Gerais, Brazil), respectively. Serum concentrations of total cholesterol (TC) and highdensity lipoprotein cholesterol (HDL-c) were measured using the Trinder enzymatic method and the accelerator selective detergent method using Liquiform Cholesterol and HDL LE kits (Labtest ${ }^{\circledR}$, Minas Gerais, Brazil), respectively. Triglycerides (TG) levels were determined using the Trinder method with a TAG Liquiform kit (Labtest ${ }^{\oplus}$, Minas Gerais, Brazil). All analyses followed the manufacturers recommendations and absorbance was determined using a LabMax 240 Premium automatic analyzer (Labtest ${ }^{\oplus}$, Minas Gerais, Brazil) at $505 \mathrm{~nm}$ (TAG), $500 \mathrm{~nm}$ (TC) or $600 \mathrm{~nm}$ (HDL) (Batista et al., 2018).

\subsection{Histopathological evaluation}

To assess if the tested strains can translocate to the liver, spleen and kidneys, fragments of these organs as well as of intestine were collected from different animals of each group. The tissue samples were washed in saline solution $(0.9 \% \mathrm{NaCl}, w / v)$, fixed in $10 \%(\mathrm{v} / \mathrm{v})$ buffered formalin for $48 \mathrm{~h}$ and processed according to the routine histological technique. The obtained slides were stained using the technique of Hematoxylin-Eosin (H\&E) as previously described (Batista et al., 2018).

Morphological analysis of liver included evaluation of the occurrence of degenerative processes by fatty degeneration and inflammatory parameters, including leucocyte migration, edema, hyperemia, hemorrhage, necrosis, preservation of liver parenchyma and presence of micro thrombi. The analysis of spleen included evaluation of inflammatory processes presence, such as stasis, leucocyte migration, hemorrhage, vasodilation and necrosis, as well as evaluation of epithelial preservation, hypertrophy and hyperplasia of the white or red pulp. The morphological analysis of kidney included evaluation (presence) of glomerulonephritis and interstitial nephritis, necrosis and degeneration. The intestine was evaluated for inflammatory processes presence, such as stasis, leucocyte migration, hemorrhage, vasodilation and necrosis, as well as for epithelial preservation, hypertrophy and hyperplasia of the outer muscular layer (Batista et al., 2018; Erben et al., 2014; Rigo et al., 2013). To confirm the observations, the slides were re-evaluated by the same pathologist after being randomized by an independent person and the general agreement between the two analyses was considered as an evaluation criterion (Wang, Li, Li, Zhang, \& Li, 2009).

\subsection{Cultivation of Lactobacillus from organs and fecal samples}

At each evaluation point, samples of liver, kidneys, spleen and intestine were mixed (1:10) in sterile saline solution, washed twice $\left(4500 \times g, 15 \mathrm{~min}, 4^{\circ} \mathrm{C}\right)$ with sterile saline solution and vortexed $(30 \mathrm{~s})$ to break down the clusters of bacteria and to remove bacteria weakly bound to the tissues. The vortexed solution was washed $(4500 \times g$, $15 \mathrm{~min}, 4^{\circ} \mathrm{C}$ ) again, the supernatant was removed and the organs were aseptically fractionated and directly plated onto MRS agar (Wang, Li, et al., 2009). For enumeration of Lactobacillus in feces, at each evaluation point, feces were collected, weighed, diluted (1:10) in sterile saline solution and homogenized for $30 \mathrm{~s}$ using a vortex. The mixture was serially diluted $\left(10^{-1}-10^{-6}\right)$ in the same diluent and $20-\mu \mathrm{L}$ aliquots of each dilution were dispensed onto MRS agar using a microdrop inoculation technique (Herigstad, Hamilton, \& Heersink, 2001). The plates were incubated at $37{ }^{\circ} \mathrm{C}$ for $48 \mathrm{~h}$ under anaerobiosis (Anaerobic System Anaerogen, Oxoid) and the results were expressed as $\log \mathrm{CFU} / \mathrm{g}$. 


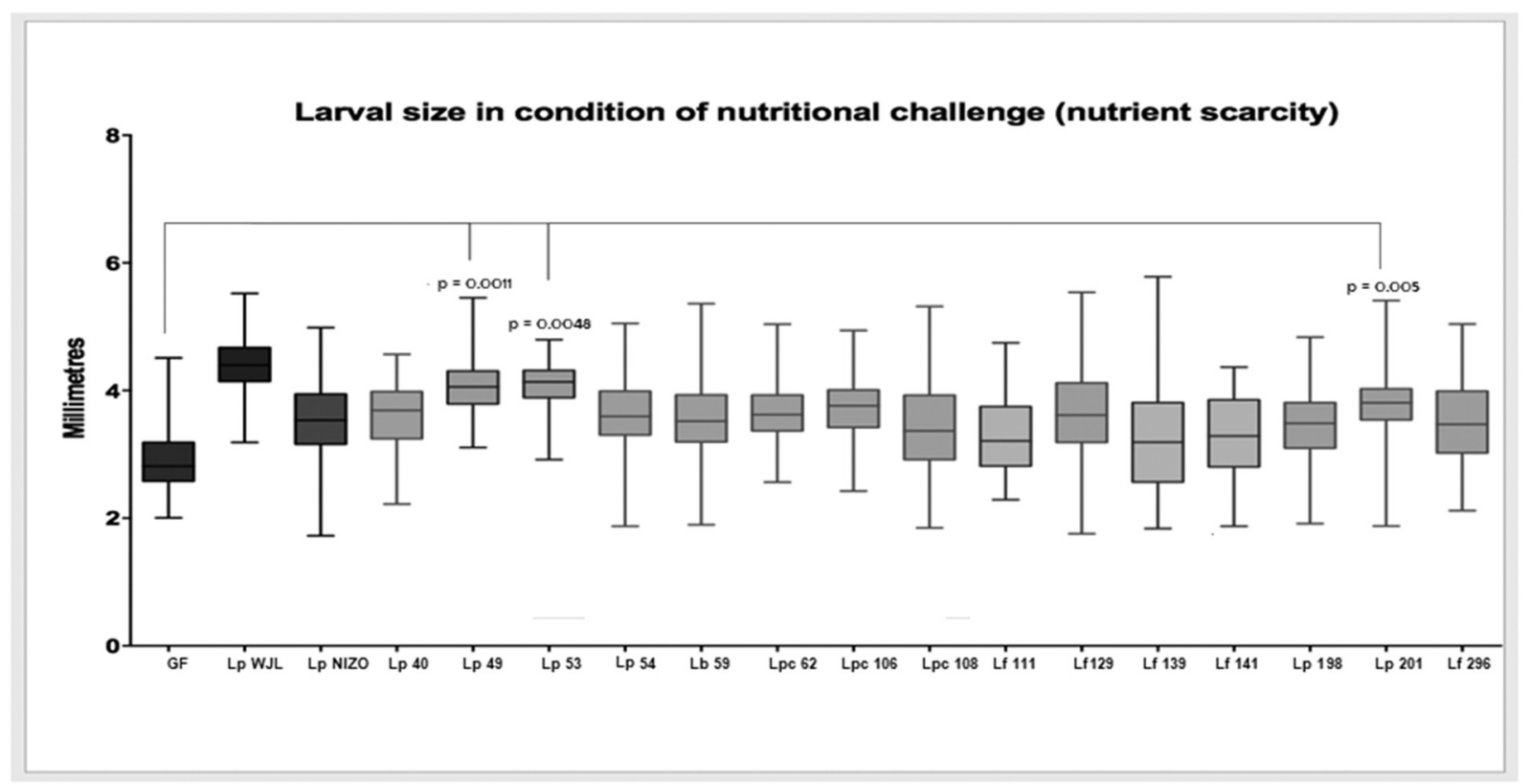

Fig. 1. Longitudinal size of larvae ( $\mathrm{n}>60$ larvae/group) measured 7 days after egg deposition on poor nutrient. Larvae were kept germ-free (GF) or associated with the respective strain of Lactobacillus: GF - germ-free; Lp WJL: L. plantarum WJL; Lp NIZO: L. plantarum NIZO2877; Lp 40: L. plantarum 40; Lp 49: L. plantarum 49; Lp 53: L. plantarum 53; Lb 54: Lactobacillus plantarum 54; Lb 59: Lactobacillus brevis 59; Lpc 62: L. paracasei 62; Lpc 106: L. paracasei 106; Lpc 108: L. paracasei 108; Lf 111 L. fermentum 111; Lf 129: L. fermentum 129; Lf 139: L. fermentum 139; Lf 141: L. fermentum 141; Lp 198: L. plantarum 198; Lp 201: L. plantarum 201; Lf 210: L. fermentum 210. Indicative lines show the fruit-derived Lactobacillus strains with most relevant results based on Student's $t$-test (considering the difference between the larval size of $D$. melanogaster larvae colonized and larvae of germ free (GF) D. melanogaster).

\subsection{PCR of organs and feces}

Bacterial DNA extraction from the tissues (liver, spleen, kidneys and intestine) and feces samples was performed using phenol-chloroform method (Chomczynski \& Sacchi, 1987). Briefly, each sample was frozen with liquid nitrogen and grounded to form a powder. An aliquot $(20 \mathrm{mg}$ ) was mixed with $500 \mu \mathrm{L}$ of lysis buffer (Tris-HCl/EDTA/SDS/ water) and $25 \mu \mathrm{L}$ protein kinase $\mathrm{K}(10 \mathrm{mg} / \mathrm{mL})$ and maintained for $2 \mathrm{~h}$ at $55{ }^{\circ} \mathrm{C}$ in water bath. Then, $500 \mu \mathrm{L}$ of phenol/chloroform/isoamyl alcohol (25:24:1) was added and the resulting mixture was sequentially vortexed $(30 \mathrm{~s})$, placed on the rotary shaker $(25 \mathrm{rpm}, 15 \mathrm{~min})$ and after centrifugation $\left(13,000 \times g, 27^{\circ} \mathrm{C}, 5 \mathrm{~min}\right)$ the upper aqueous phase was recovered to a new tube. The process was repeated twice. Finally, sodium acetate $3 \mathrm{mM} / \mathrm{L}(1: 10)$ and ethanol $(100 \% ; 2.5: 1$, stored at $\left.-20^{\circ} \mathrm{C}\right)$ were added to the aqueous phase, centrifuged $(13,000 \times \mathrm{g}$, $4{ }^{\circ} \mathrm{C}, 5 \mathrm{~min}$ ) and the supernatant removed. An $800 \mu \mathrm{L}$-aliquot of ethanol $\left(70 \% \mathrm{v} / \mathrm{v}\right.$; stored at $\left.-20^{\circ} \mathrm{C}\right)$ was added to the remaining pellet, centrifuged $\left(13,000 \times g, 4^{\circ} \mathrm{C}, 5 \mathrm{~min}\right)$ and the supernatant was removed. The final pellet was resuspended with RNAse free water. DNA concentration and purity $(260 / 280 \mathrm{~nm}$ absorbance ratio) was determined using a Nanodrop 2000 (Thermofisher). The samples were prepared using the PCR mix with GoTaq Promega reagents. The PCR reactions were performed in a final volume of $20 \mu \mathrm{L}$ using the specific primers designed for L. plantarum 49 or L. plantarum 201 and analyzed as described in Section 2.2.1.

\subsection{Reproducibility and statistical analysis}

For D. melanogaster assays, statistical difference between the larval size of $D$. melanogaster larvae colonized with strains tested and larvae of germ free (GF) D. melanogaster was assessed using Student's $t$-test. Samples with values of $\mathrm{p} \leq .05$ were considered statistically different. For assays in rats, statistical power of $1.0(100 \%)$ was obtained using the software SigmaPlot 12.5 for Windows (Systat Software Inc.) by estimating forty-eight male Wistar rats (sixteen per group) when the minimally detectable effect size was 0.8 and the significance level was $0.05(\mathrm{p} \leq .05)$. The results were expressed as means and standard deviation of three independent experiments performed in triplicate. Statistical analyses were performed to determine significant differences ( $\mathrm{p} \leq .05$ ) using ANOVA followed by post hoc Turkey test or Student's $t$ test. Sigma Stat 3.5 computer software (Jandel Scientific Software, San Jose, California) was used for the statistical analyses of the data.

\section{Results}

\subsection{Screening of Lactobacillus strains using a nutrient scarcity model}

The strains L. plantarum WJL, L. plantarum 49, L. plantarum 53 and $L$. plantarum 201 showed the most significant $(\mathrm{p} \leq .005)$ growth promoting effects on $D$. melanogaster upon the nutrient scarcity environment test (Fig. 1). The larvae colonized with these strains exhibited sizes approximately two-fold higher $(\mathrm{p} \leq .05)$ than those observed for larvae of germ free (GF) D. melanogaster when submitted to the same nutrient reduction. L. plantarum 40, L. plantarum 189, L. fermentum 296, L. paracasei 62 , L. paracasei 106 , L. paracasei 108 , L. brevis 54 , L. brevis 59 and $L$. fermentum 129 strains also promoted $D$. melanogaster larval growth. Otherwise, L. fermentum 111, L. fermentum 139 and L. fermentum 144 strains did not show any growth-promoting effects, with results similar ( $\mathrm{p}>.05$ ) to GF D. melanogaster. Phylogenetic analysis on their 16S rRNA gene sequences revealed that $L$. plantarum 49 (isolated from pulp of barbados cherry) and $L$. plantarum 53 (isolated from byproduct of barbados cherry) were closely related, while L. plantarum 201 (isolated from pulp of mango) showed higher distance in the evolutionary chain (Supplementary Fig. 1). Therefore, L. plantarum 49 and L. plantarum 201 strains were selected for genome sequencing and in vivo studies.

Based on the results of whole genome analysis of L. plantarum 49 (GeneBank number QBKW00000000) and L. plantarum 201 (GeneBank number QBKX00000000), specific primers were designed. L. plantarum 49 specific feature is the presence of a different domain ( $800 \mathrm{bp}$ ) in lp_0946 (mucus binding protein) compared to the other lactobacilli (Fig. 2A-B). Based on this domain, the primers 5'-GGCATCGACCTCCG 

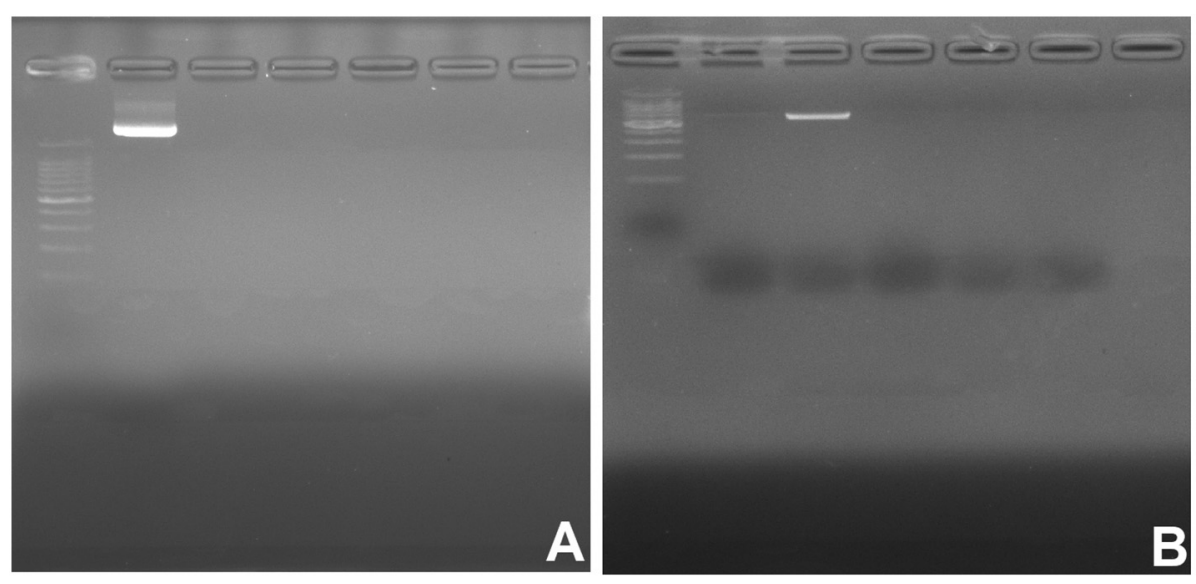

Fig. 2. Fragments resulting polymerase chain reaction (PCR) products using the designed primers to $L$. plantarum 49 and L. plantarum 201 separated by $1.0 \%$ agarose gel electrophoresis (A). Line 1 corresponds to molecular size marker of $100 \mathrm{bp}$; Line 2: fragments observed for L. plantarum 49 (Lp 49); Line 3 L. plantarum 201 (Lp 201); Line 4: L. plantarum NIZO2877 (Lp NIZO); Line 5: L. plantarum WJL (Lp WJL); Line 6: L. plantarum WCFS1 (Lp WCFS1); Line 7: L. plantarum NC8 (Lp NC8). (B) Line 1 corresponds to molecular size marker of $100 \mathrm{bp}$; Line 2: L. plantarum 49 (Lp 49); Line 3: fragments observed for $L$. plantarum 201 (Lp 201); Line 4: L. plantarum NIZO2877 (Lp NIZO); Line 5: L. plantarum WJL (Lp WJL); Line 6: L. plantarum WCFS1 (Lp WCFS1); Line 7: L. plantarum NC8 (Lp NC8).

Table 2

Food intake and murine parameters of Wistar male rats during 28 days of administration of L. plantarum 49 and L. plantarum 201 and wash-out.

\begin{tabular}{|c|c|c|c|c|}
\hline \multicolumn{5}{|c|}{ Food intake and murine parameters } \\
\hline \multirow[t]{2}{*}{ Indicator } & \multirow[t]{2}{*}{ Period } & \multicolumn{3}{|l|}{ Groups } \\
\hline & & Control & L. plantarum 49 & L. plantarum 201 \\
\hline \multirow[t]{4}{*}{ Food intake $(g)$} & Before & $23.18 \pm 3.43^{\mathrm{Aa}}$ & $21.30 \pm 2.19^{\mathrm{Aa}}$ & $22.11 \pm 2.54^{\mathrm{Aa}}$ \\
\hline & 14 days & $22.56 \pm 2.74^{\mathrm{Aa}}$ & $22.44 \pm 1.62^{\mathrm{Aa}}$ & $21.19 \pm 2.91 \mathrm{Aa}$ \\
\hline & 28 days & $24.46 \pm 3.26^{\mathrm{Aa}}$ & $22.59 \pm 1.57^{\text {Аа }}$ & $21.87 \pm 1.58^{\mathrm{Aa}}$ \\
\hline & Wash-out & $19.64 \pm 3.28^{\mathrm{Aa}}$ & $22.05 \pm 3.61$ Аa & $22.94 \pm 3.49^{\mathrm{Aa}}$ \\
\hline \multirow[t]{4}{*}{ Body weight (g) } & Before & $228.12 \pm 22.30^{\mathrm{Aa}}$ & $218.75 \pm 16.01 \mathrm{Aa}$ & $219.37 \pm 19.62^{\mathrm{Aa}}$ \\
\hline & 14 days & $258.12 \pm 22.27^{\mathrm{Aa}}$ & $261.87 \pm 17.26^{\mathrm{Aa}}$ & $259.69 \pm 16.68^{\mathrm{Aa}}$ \\
\hline & 28 days & $287.45 \pm 19.44$ & $290.48 \pm 17.32$ Аа & $290.25 \pm 16.18$ \\
\hline & Wash-out & $311.63 \pm 20.21 \mathrm{Aa}$ & $318.44 \pm 11.29^{\mathrm{Aa}}$ & $319.06 \pm 15.65^{\mathrm{Aa}}$ \\
\hline \multirow[t]{4}{*}{ Body length (cm) } & Before & $22.37 \pm 1.11 \mathrm{Aa}$ & $21.37 \pm 1.49^{\mathrm{Aa}}$ & $22.00 \pm 1.22^{\mathrm{Aa}}$ \\
\hline & 14 days & $22.37 \pm 0.75^{\mathrm{Aa}}$ & $22.37 \pm 1.49^{\mathrm{Aa}}$ & $23.12 \pm 1.03 \mathrm{Aa}$ \\
\hline & 28 days & $24.12 \pm 1.31$ Аa & $23.5 \pm 0.71^{\mathrm{Aa}}$ & $23.00 \pm 0.82^{\mathrm{Aa}}$ \\
\hline & Wash-out & $24.37 \pm 0.75^{\mathrm{Aa}}$ & $24.00 \pm 1.15^{\mathrm{Aa}}$ & $23.50 \pm 0.87^{\mathrm{Aa}}$ \\
\hline \multirow[t]{4}{*}{ Body mass index $\left(\mathrm{g} / \mathrm{cm}^{2}\right)$} & Before & $0.46 \pm 0.0^{\mathrm{Aa}}$ & $0.48 \pm 0.05^{\mathrm{Aa}}$ & $0.46 \pm 0.07^{\mathrm{Aa}}$ \\
\hline & 14 days & $0.52 \pm 0.05^{\mathrm{Aa}}$ & $0.48 \pm 0.05^{\mathrm{Aa}}$ & $0.49 \pm 0.03^{\mathrm{Aa}}$ \\
\hline & 28 days & $0.55 \pm 0.06^{\mathrm{Aa}}$ & $0.53 \pm 0.05^{\mathrm{Aa}}$ & $0.55 \pm 0.02^{\mathrm{Aa}}$ \\
\hline & Wash-out & $0.53 \pm 0.05^{\mathrm{Aa}}$ & $0.55 \pm 0.04^{\mathrm{Aa}}$ & $0.58 \pm 0.02^{\mathrm{Aa}}$ \\
\hline \multirow[t]{4}{*}{ Lee index $(\mathrm{g} / \mathrm{cm})$} & Before & $0.27 \pm 0.02^{\mathrm{Aa}}$ & $0.28 \pm 0.01 \mathrm{Aa}$ & $0.27 \pm 0.02^{\mathrm{Aa}}$ \\
\hline & 14 days & $0.28 \pm 0.01^{\mathrm{Aa}}$ & $0.27 \pm 0.02^{\mathrm{Aa}}$ & $0.28 \pm 0.01^{\mathrm{Aa}}$ \\
\hline & 28 days & $0.27 \pm 0.01^{\mathrm{Aa}}$ & $0.28 \pm 0.01^{\mathrm{Aa}}$ & $0.29 \pm 0.01^{\mathrm{Aa}}$ \\
\hline & Wash-out & $0.28 \pm 0.01^{\mathrm{Aa}}$ & $0.29 \pm 0.01^{\mathrm{Aa}}$ & $0.29 \pm 0.01^{\mathrm{Aa}}$ \\
\hline \multirow[t]{4}{*}{ Thoracic circunference $(\mathrm{cm})$} & Before & $13.12 \pm 1.25^{\mathrm{Aa}}$ & $13.12 \pm 0.75^{\text {Аа }}$ & $13.62 \pm 1.8^{\mathrm{Aa}}$ \\
\hline & 14 days & $13.62 \pm 1.03^{\mathrm{Aa}}$ & $13.87 \pm 1.65^{\text {Аа }}$ & $14.25 \pm 1.5^{\mathrm{Aa}}$ \\
\hline & 28 days & $14.50 \pm 0.82^{\mathrm{Aa}}$ & $14.62 \pm 1.03^{\mathrm{Aa}}$ & $14.05 \pm 0.42^{\mathrm{Aa}}$ \\
\hline & Wash-out & $14.62 \pm 0.95^{\mathrm{Aa}}$ & $14.12 \pm 0.25^{\mathrm{Aa}}$ & $14.37 \pm 1.49^{\mathrm{Aa}}$ \\
\hline \multirow[t]{4}{*}{ Abdominal circunference $(\mathrm{cm})$} & Before & $14.25 \pm 1.25^{\mathrm{Aa}}$ & $14.62 \pm 0.48^{\mathrm{Aa}}$ & $16.00 \pm 1.82^{\mathrm{Aa}}$ \\
\hline & 14 days & $15.25 \pm 1.32^{\mathrm{Aa}}$ & $14.75 \pm 1.71^{\mathrm{Aa}}$ & $15.62 \pm 1.8^{\mathrm{Aa}}$ \\
\hline & 28 days & $15.87 \pm 1.03^{\mathrm{Aa}}$ & $15.62 \pm 1.03^{\mathrm{Aa}}$ & $15.00 \pm 0.41 \mathrm{Aa}$ \\
\hline & Wash-out & $16.00 \pm 1.78^{\mathrm{Aa}}$ & $14.62 \pm 0.48^{\mathrm{Aa}}$ & $15.50 \pm 2.12^{\mathrm{Aa}}$ \\
\hline
\end{tabular}

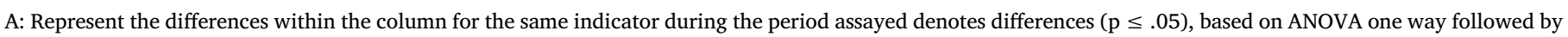
post hoc Turkey test.

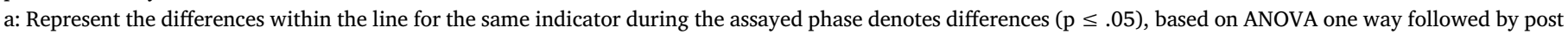
hoc Turkey test.

TTAAAT-3' (forward) and 5'-CAATCAACACCAACCACCTT-3' (reverse) were designed as strain-specific for L. plantarum 49. They do not amplify the genome of any other of the tested L. plantarum strains (Fig. 2B).

L. plantarum 201 specific feature was a large insertion (about $10 \mathrm{~kb}$ ) of an unknown protein between lp_0045 (ribosomal RNA large subunit methyltransferase $\mathrm{H}$ ) and lp_0046 (transcription regulator, TetR family) (Fig. 2C). The primers 5'-GGTTTATCGGGCGTTTATGA-3' (forward) and 5'-CCAAACTCCACCAATTAGCA-3' (reverse) were designed on this region to specifically amplify L. plantarum 201 strain. They did not amplify the genome of any other $L$. plantarum strain tested.

\subsection{Murinometric parameters}

During the experimental or wash-out period, animals of group Lp49, Lp201 and control showed similar $(\mathrm{p}>.05)$ daily food intake. No differences $(p>.05)$ were observed in the murinometric parameters (AC, TCi, body length, body weight, BMI and LI) of Lp49 or Lp201 group compared to those of control group (Table 2).

\subsection{Serum analysis and lipid profile}

No change was observed in glucose levels of control group over the assayed period (intervention and wash-out). After 28 days of 
Table 3

Biochemical parameters of Wistar male rats during 28 days of administration of L. plantarum 49 and L. plantarum 201 and wash-out.

\begin{tabular}{|c|c|c|c|c|}
\hline \multicolumn{5}{|l|}{ Biochemical parameters } \\
\hline \multirow[t]{2}{*}{ Marker } & \multirow[t]{2}{*}{ Period } & \multicolumn{3}{|l|}{ Groups } \\
\hline & & Control & L. plantarum 49 & L. plantarum 201 \\
\hline \multirow[t]{4}{*}{ Glucose (mg/dL) } & Before & $92.75 \pm 1.71 \mathrm{Aa}$ & $91.25 \pm 1.89^{\mathrm{Aa}}$ & $92.75 \pm 0.50^{\mathrm{Aa}}$ \\
\hline & 14 days & $93.00 \pm 1.15^{\mathrm{Aa}}$ & $93.75 \pm 0.96^{\mathrm{Aa}}$ & $93.50 \pm 0.58^{\mathrm{Aa}}$ \\
\hline & 28 days & $92.75 \pm 0.96^{\mathrm{Aa}}$ & $80.25 \pm 1.50^{\mathrm{Bb}}$ & $82.50 \pm 1.12^{\mathrm{Bb}}$ \\
\hline & Wash-out & $92.25 \pm 0.96^{\mathrm{Aa}}$ & $80.75 \pm 1.26^{\mathrm{Bb}}$ & $92.75 \pm 1.29^{\mathrm{Aa}}$ \\
\hline \multirow[t]{4}{*}{ Total cholesterol (mg/dL) } & Before & $63.00 \pm 0.20^{\mathrm{Aa}}$ & $62.25 \pm 1.50^{\mathrm{Aa}}$ & $63.75 \pm 0.96^{\mathrm{Aa}}$ \\
\hline & 14 days & $62.25 \pm 1.26^{\mathrm{Aa}}$ & $50.62 \pm 0.75^{\mathrm{Bb}}$ & $42.75 \pm 1.50^{\mathrm{Bb}}$ \\
\hline & 28 days & $64.00 \pm 1.41^{\mathrm{Aa}}$ & $51.25 \pm 0.96^{\mathrm{Bb}}$ & $42.25 \pm 0.96^{\mathrm{Bb}}$ \\
\hline & Wash-out & $62.75 \pm 1.26^{\mathrm{Aa}}$ & $63.00 \pm 0.82^{\mathrm{Aa}}$ & $42.50 \pm 1.29^{\mathrm{Bb}}$ \\
\hline \multirow[t]{4}{*}{ Triglycerides (mg/dL) } & Before & $99.50 \pm 1.29^{\mathrm{Aa}}$ & $99.50 \pm 1.73^{\mathrm{Aa}}$ & $99.50 \pm 0.58^{\mathrm{Aa}}$ \\
\hline & 14 days & $99.25 \pm 1.71^{\mathrm{Aa}}$ & $98.75 \pm 0.96^{\mathrm{Aa}}$ & $99.00 \pm 1.41^{\mathrm{Aa}}$ \\
\hline & 28 days & $99.12 \pm 0.58^{\mathrm{Aa}}$ & $98.75 \pm 0.50^{\mathrm{Aa}}$ & $99.00 \pm 0.82^{\mathrm{Aa}}$ \\
\hline & Wash-out & $99.75 \pm 0.96^{\mathrm{Aa}}$ & $99.50 \pm 1.29^{\mathrm{Aa}}$ & $99.25 \pm 1.71 \mathrm{Aa}$ \\
\hline \multirow[t]{4}{*}{ HDL cholesterol (mg/dL) } & Before & $24.00 \pm 0.82^{\mathrm{Aa}}$ & $24.25 \pm 0.96^{\mathrm{Aa}}$ & $24.25 \pm 1.26^{\mathrm{Aa}}$ \\
\hline & 14 days & $24.50 \pm 0.58^{\mathrm{Aa}}$ & $25.00 \pm 0.82^{\mathrm{Aa}}$ & $24.25 \pm 0.50^{\mathrm{Aa}}$ \\
\hline & 28 days & $24.29 \pm 0.85^{\mathrm{Aa}}$ & $24.70 \pm 0.68^{\mathrm{Aa}}$ & $25.00 \pm 0.72^{\mathrm{Aa}}$ \\
\hline & Wash-out & $24.97 \pm 0.84^{\mathrm{Aa}}$ & $25.30 \pm 0.53^{\mathrm{Aa}}$ & $25.07 \pm 0.76^{\mathrm{Aa}}$ \\
\hline \multirow[t]{4}{*}{ ALT (U/L) } & Before & $152.75 \pm 1.26^{\mathrm{Aa}}$ & $151.50 \pm 1.29^{\mathrm{Aa}}$ & $152.75 \pm 0.96^{\mathrm{Aa}}$ \\
\hline & 14 days & $153.87 \pm 0.85^{\mathrm{Aa}}$ & $153.25 \pm 1.50^{\mathrm{Aa}}$ & $153.10 \pm 0.67^{\mathrm{Aa}}$ \\
\hline & 28 days & $153.01 \pm 1.32 \mathrm{Aa}$ & $152.62 \pm 0.82^{\mathrm{Aa}}$ & $153.11 \pm 1.53^{\mathrm{Aa}}$ \\
\hline & Wash-out & $153.67 \pm 1.05^{\mathrm{Aa}}$ & $153.93 \pm 0.82 \mathrm{Aa}$ & $153.67 \pm 0.83^{\mathrm{Aa}}$ \\
\hline \multirow[t]{4}{*}{ AST (U/L) } & Before & $51.62 \pm 1.38^{\mathrm{Aa}}$ & $51.75 \pm 0.96^{\mathrm{Aa}}$ & $52.51 \pm 1.08^{\mathrm{Aa}}$ \\
\hline & 14 days & $52.67 \pm 0.79^{\mathrm{Aa}}$ & $52.21 \pm 0.92^{\mathrm{Aa}}$ & $52.40 \pm 0.98^{\mathrm{Aa}}$ \\
\hline & 28 days & $52.84 \pm 0.99^{\mathrm{Aa}}$ & $53.00 \pm 1.15^{\mathrm{Aa}}$ & $52.16 \pm 0.89^{\mathrm{Aa}}$ \\
\hline & Wash-out & $51.75 \pm 0.95^{\mathrm{Aa}}$ & $52.51 \pm 1.09^{\mathrm{Aa}}$ & $52.85 \pm 0.92^{\mathrm{Aa}}$ \\
\hline
\end{tabular}

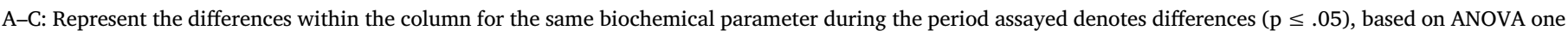
way followed by post hoc Turkey test;

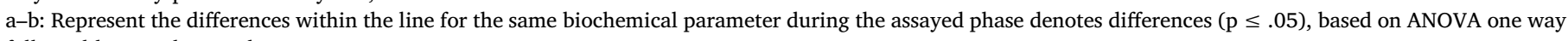
followed by post hoc Turkey test.

administration, $L p 49$ and $L p 201$ groups showed a reduction ( $\mathrm{p} \leq .05)$ in glucose levels. Only in $L p 49$ group, glucose levels remained reduced during the wash-out period (Table 3 ).

No change was observed in TC levels of control group during the intervention or wash-out periods. Lp49 and Lp201 groups showed a reduction $(\mathrm{p} \leq .05)$ of TC levels after 14 days of intervention. In both groups, no additional changes $(\mathrm{p}>.05)$ were observed after 28 days of intervention. However, after the wash-out period, the TC levels remained reduced in the $L p 201$ group, while in $L p 49$ group, they returned to the baseline levels. No difference ( $p>.05$ ) was observed in TG, ALT and AST serum levels among the control, Lp49 or Lp201 groups throughout the period monitored (intervention or wash-out).

\subsection{Histopathological evaluation}

No translocated cells were observed in intestine, spleen, kidneys or liver collected from animals of Lp49 and Lp201 groups. No morphological differences $(\mathrm{p}>.05)$ were observed among Lp49, Lp201 and control groups (Fig. 3). The weight of organs and abdominal fat were similar ( $>$.05) between Lp49, Lp201 and control groups during the experimental and wash-out periods (Supplementary Table 1).

\subsection{Microbiological and PCR analysis of organs and feces}

No viable cell count of Lactobacillus spp. was observed by plating suspension of liver, spleen or kidneys of animals from Lp49, Lp201 or control groups in MRS agar. No amplification of the fragments of $800 \mathrm{bp}$, corresponding to L. plantarum 49 , or $600 \mathrm{bp}$ corresponding to $L$. plantarum 201 was observed (no band was visualized in the electrophoresis) when these same organs were submitted to PCR analysis using the strain-specific primers.

No change ( $\mathrm{p}>.05$ ) in counts of Lactobacillus spp. was observed in intestine or feces of control group over the period monitored (experimental and wash-out) (Table 4). Otherwise, Lactobacillus counts increased $(\mathrm{p} \leq .05)$ approximately $1.2 \mathrm{log}$ CFU/g after 14 days of intervention in feces and intestine of $L p 49$ and $L p 201$ groups. An additional increase ( $\mathrm{p} \leq .05)$ of approximately $2 \log \mathrm{CFU} / \mathrm{mL}$ was observed in these groups after 28 days of intervention. After the wash-out period, Lactobacillus counts decreased $(\mathrm{p} \leq .05)$ to levels similar $(\mathrm{p}>.05)$ to those observed at 14 days of intervention in both Lp49 and Lp201 groups. PCR analysis of the colonies grown in MRS agar inoculated with suspensions of intestine and feces revealed the amplification of the 800 bp and 600 bp fragments in Lp49 and Lp201 groups, respectively, identical to those presented on Fig. 3. No amplification of these same fragments was observed in feces of control group.

\section{Discussion}

D. melanogaster mono- or poly-associated with lactobacilli strains constitutes a powerful model to evaluate the complex interplay between lactobacilli and host biologic traits (Matos \& Leulier, 2014). The effects on D. melanogaster growth varied among the Lactobacillus strains tested. Strains of the same or distinct Lactobacillus species may be phenotypically heterogeneous regarding the guanine/cytosine contents, type of cell wall peptidoglycan, and, most importantly, regarding the metabolic profile, defined in terms of types of fermented sugars and fermentation end-products, upon which traditional taxonomic analysis is based (Salvetti, Torriani, \& Felis, 2012). The sum of these factors probably defined the ability of each strain to promote $D$. melanogaster growth in a specific manner under nutrient scarcity.

The greater ( $\mathrm{p} \leq .005)$ growth-promoting effects of L. plantarum 49, L. plantarum 53 and L. plantarum 201 when compared to other tested strains could be also related to the specific capability of these strains of using the available nutrients and produce a variety of metabolites that may influence D. melanogaster larval growth (Park et al., 2017; Shanahan, 2012). A previous study demonstrated that L. plantarum WJL 


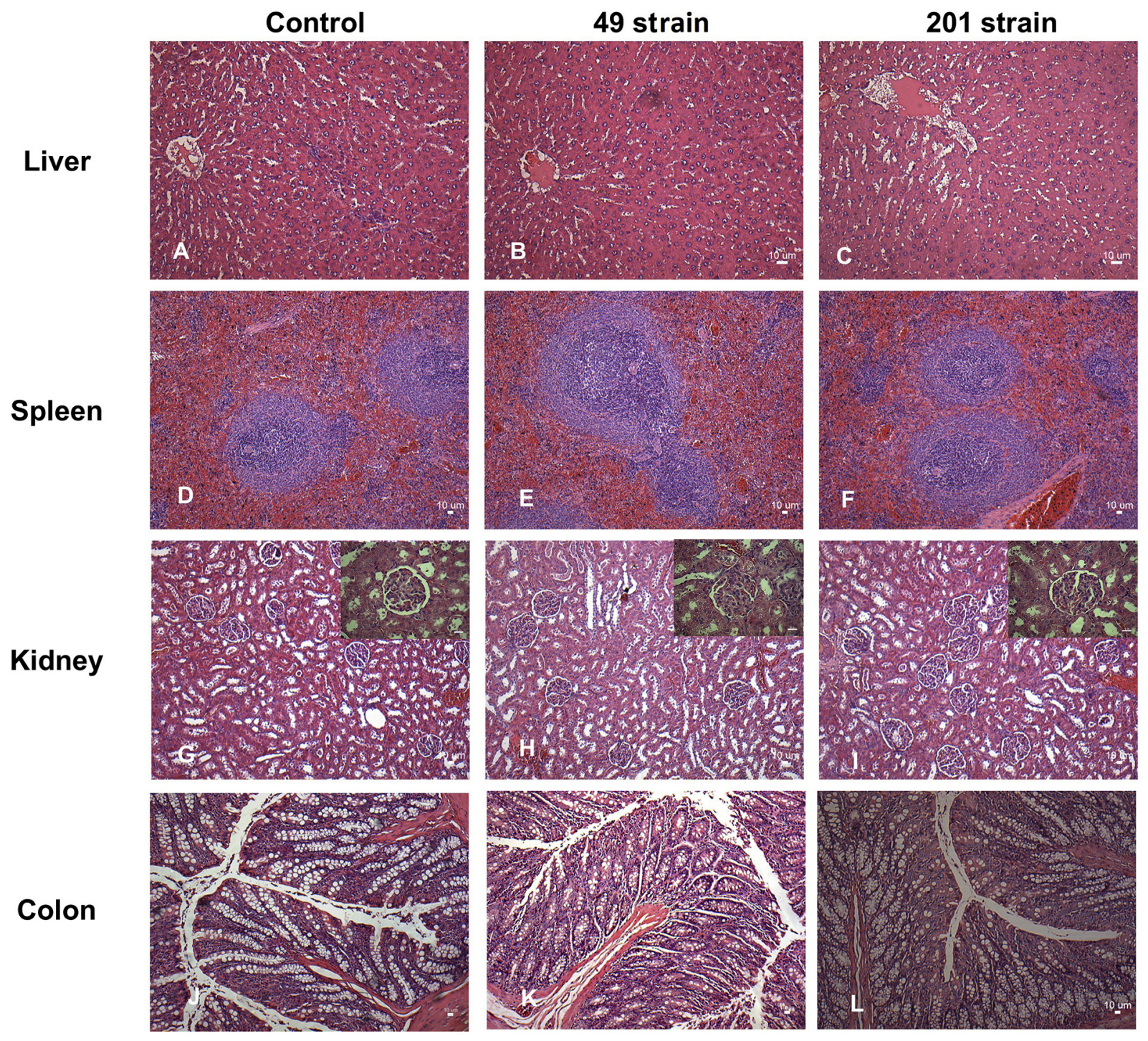

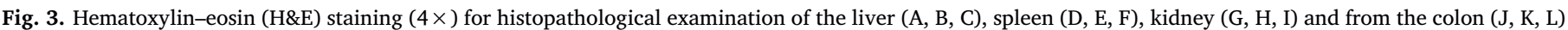
of the control group and groups receiving L. plantarun 49 or L. plantarum 201 during the 28 days.

Table 4

Viable counts (log CFU/g) of Lactobacillus spp. in intestine and feces from Wistar male rats of control, L. plantarum 49 and L. plantarum 201 group through the experimental designed period.

\begin{tabular}{|c|c|c|c|c|}
\hline \multicolumn{5}{|c|}{ Lactobacillus spp. counts } \\
\hline \multirow[t]{2}{*}{ Source } & \multirow[t]{2}{*}{ Period } & \multicolumn{3}{|l|}{ Groups } \\
\hline & & Control & L. plantarum 49 & L. plantarum 201 \\
\hline \multirow[t]{4}{*}{ Intestine } & Before & $2.88 \pm 0.57^{\mathrm{Aa}}$ & $2.86 \pm 0.41 \mathrm{Aa}$ & $2.85 \pm 0.27^{\mathrm{Aa}}$ \\
\hline & 14 days & $2.96 \pm 0.69^{\mathrm{Aa}}$ & $4.69 \pm 0.52^{\mathrm{Bb}}$ & $5.05 \pm 0.33^{\mathrm{Bb}}$ \\
\hline & 28 days & $3.09 \pm 0.52^{\mathrm{Aa}}$ & $6.62 \pm 0.45^{\mathrm{Cb}}$ & $7.06 \pm 0.39^{\mathrm{Cb}}$ \\
\hline & Wash-out & $3.18 \pm 0.59^{\mathrm{Aa}}$ & $4.59 \pm 0.58^{\mathrm{Bb}}$ & $5.03 \pm 0.52^{\mathrm{Bb}}$ \\
\hline \multirow[t]{4}{*}{ Feces } & Before & $9.04 \pm 0.19^{\mathrm{Aa}}$ & $9.03 \pm 0.41 \mathrm{Aa}$ & $9.11 \pm 0.22^{\mathrm{Aa}}$ \\
\hline & 14 days & $9.08 \pm 0.59^{\mathrm{Aa}}$ & $10.62 \pm 0.35^{\mathrm{Bb}}$ & $10.86 \pm 0.45^{\mathrm{Bb}}$ \\
\hline & 28 days & $8.99 \pm 0.52^{\mathrm{Aa}}$ & $12.55 \pm 0.72^{\mathrm{Cb}}$ & $12.45 \pm 0.33^{\mathrm{Cb}}$ \\
\hline & Wash-out & $8.96 \pm 0.69^{\mathrm{Aa}}$ & $10.56 \pm 0.48^{\mathrm{Bb}}$ & $10.06 \pm 0.30^{\mathrm{Bb}}$ \\
\hline
\end{tabular}

A-C: Represent the differences within the column for the same source of strains counts during the period assayed denotes differences $(p \leq .05)$, based on ANOVA one way followed by post hoc Turkey test;

a-b: Represent the differences within the line for the same source of strains counts during the assayed phase denotes differences $(p \leq .05)$, based on ANOVA one way followed by post hoc Turkey test. was capable of stimulating larval $D$. melanogaster growth under nutrient scarcity by promoting an upstream step of TOR-dependent pathway that controls hormonal growth signaling (Storelli et al., 2011). In agreement with these previous results, our findings indicate that $L$. plantarum 49, L. plantarum 53 and L. plantarum 201 may also influencing the $D$. melanogaster growth and modulate its physiological processes.

Administration of L. plantarum 49 and L. plantarum 201 did not change food intake and morphometric parameters in healthy rats. These finding are in accordance with results reported for healthy female Wistar rats receiving L. plantarum Lp62 during 27 days (Messias et al., 2018). However, reduction in body weight gain was observed in rats fed with a high-fat diet receiving a mixture of $L$. plantarum $(L$. plantarum CECT 7527, 7528, and 7529; approximately $9 \log$ CFU/day) during 8 weeks (Kim et al., 2014). Difference in findings among studies supports strain-specific effects of L. plantarum (Park et al., 2017; Shanahan, 2012).

L. plantarum 49 and L. plantarum 201 decreased the serum glucose levels in rats after 28 days of administration. The $\alpha$-glucosidase inhibitory activity, already identified in Lactobacillus (Chen et al., 2014a), has been suggested as one possible mechanism underlying the antidiabetic effects of some probiotic strains (Chen et al., 2014a, 2014b). $\mathrm{L}$. 
plantarum CCFM0236 (approximately $10 \log$ CFU/day for 7 weeks) has shown able to control glucose and ameliorate insulin resistance in highfat and streptozotocin induced diabetes in rats ( $\mathrm{Li}$ et al., 2016a). Nevertheless, the hypoglycemic effect of L. plantarum X1 (9 log CFU/ day for 10 weeks) was cited as strongly associated with changes in gut microbiota and short-chain fatty acids production (Li et al., 2016b). Further studies using diabetic rats should clarify possible hypoglycemic effects caused by L. plantarum 49 and L. plantarum 201 and the underlying mechanisms. Overall, during the wash-out period the serum glucose levels returned to baseline values in Lp201, but not in Lp49 group, indicating an intrinsic ability of $L$. plantarum 49 to induce long lasting effects on glycemic control.

L. plantarum 49 and L. plantarum 201 decreased TC serum levels after 14 days of administration. Similar results were already observed in rats fed with a high-fat diet receiving L. plantarum (approximately $9 \log$ $\mathrm{CFU} /$ day/rat) for 8 weeks (Kim et al., 2014). High TC serum levels could indicate a higher atherogenic risk (Grundy et al., 2014). An earlier study suggested the inhibition of cholesterol reabsorption in the intestine as a possible mechanism involved in the decrease of serum TC and TG levels in rats fed a cholesterol-rich diet receiving L. plantarum MA2 (11 log CFU/day) (Wang, Xu, et al., 2009). Administration of probiotics to modulate the intestinal microbiota has been also considered as a protective strategy for dyslipidemia and non-alcoholic fatty liver disease (Kim et al., 2016). Previous study has shown that a probiotic-supplemented diet inhibited the increase of TC and TG levels, as well as promoted the increase in HDL-c level in vitro and in type 2 diabetic C57 BL/6 J mice (Chen et al., 2014a, 2014b). However, it is important to consider that the reduction of glucose and cholesterol levels in the present study was observed in healthy rats, and thus does not necessarily imply the same reduction in a disease model. After the wash-out period, TC returned to the baseline levels in Lp49, but not in Lp201 group, indicating that strain specific features, such as ability to reduce lipid accumulation or disturbing bile acid reabsorption already proposed as mechanism for induction of these effects by probiotics (Delgado, Tamashiro, \& Pastore, 2010), could be implicated with the observed results.

L. plantarum 49 and L. plantarum 201 did not translocate or promote morphological changes in rat organs, being in accordance with findings of previous studies in healthy female Wistar rats after administration of L. plantarum L2 (9 log CFU/day) for 28 days (Wang, Li, et al., 2009) or L. plantarum Lp62 (approximately $9 \log$ CFU/day) for 27 days (Messias et al., 2018).

Lactobacillus ssp. counts increased over the administration period in Lp49 and Lp201 groups and the presence of L. plantarum 49 and $L$. plantarum 201 in feces was confirmed by PCR assays. Despite the decreases observed during the wash-out period, the counts of Lactobacillus in Lp49 and Lp201 groups were higher than those found at the beginning of the experimental period. These are important results indicating that L. plantarum 49 and L. plantarum 201 are able to survive and colonize the rat gastrointestinal tract (Tuohy et al., 2007). A previous study observed increase in counts of Lactobacillus casei Shirota in feces of healthy Chinese adults ( $100 \mathrm{~mL}$ of beverage; $8 \log \mathrm{CFU} / \mathrm{mL})$ after a 14 day administration period and a sharp decrease in these counts -21 days after the end of the administration (Wang et al., 2015). Overall, only the recovery of L. plantarum 49 and L. plantarum 201 in feces did not give complete information to indicate the site of colonization, but the positive results observed in PCR assays with DNA extracted from epithelial surface cultures indicate the occurrence of epithelial colonization by the tested strains (Wang, Li, et al., 2009).

\section{Conclusion}

The screening based on growth-promoting effects in D. melanogaster was efficient to identify, among several fruit-derived Lactobacillus strains, those presenting potential probiotic features with beneficial effects on health. Using this innovative strategy, the strains L. plantarum
49 and L. plantarum 201 displayed the highest growth-promoting effects in $D$. melanogaster test, and were selected to use in further experiments using healthy adult male Wistar rats. L. plantarum 49 and L. plantarum 201 reduced glucose and TC serum levels in rats during the administration period. Interestingly, these effects remained after 14 days of the wash-out period on glucose levels only for L. plantarum 49 and on TC levels only for $L$. plantarum 201 . These results clearly pointed that health benefits and probiotic effects of lactobacilli are strain-specific and indicate L. plantarum 49 and L. plantarum 201 as potential candidates for use in management of biochemical parameters of interest in metabolic diseases.

Supplementary data to this article can be found online at https:// doi.org/10.1016/j.foodres.2018.08.035.

\section{Acknowledgments}

Authors thank the Coordination of Improvement of Higher Education Personnel (CAPES, Brazil) for the PDSE scholarship awarded to the first author (W.K.A. da Costa) and the National Council for Scientific and Technological Development (CNPq - Brazil). Authors gratefully acknowledge Benjamin Gillet and Sandrine Hughes for the sequencing service provided at the IGFL sequencing platform (Lyon, France).

\section{References}

Albuquerque, T. M. R., Garcia, E. F., Araújo, A. O., Magnani, M., Saarela, M., \& Souza, E. L. (2017). In vitro characterization of Lactobacillus strains isolated from fruit processing by-products as potential probiotics. Probiotics \& Antimicrobial Proteins, 1-13. https://doi.org/10.1007/s12602-017-9318-2.

Aziz, R. K., Bartels, D., Best, A. A., Dejongh, M., Disz, T., Edwards, R. A., ... Zagnitko, O. (2008). The RAST server: Rapid annotations using Subsystems Technology. BioMed Central Genomics, 9, 75. https://doi.org/10.1186/1471-2164-9-75.

Batista, K. S., Alves, A. F., Lima, M. S., Silva, L. A., Lins, P. P., Gomes, J. A. S., ... Aquino, J. S. (2018). Beneficial effects of consumption of acerola, cashew or guava processing by-products on intestinal health and lipid metabolism in dislipidaemic female Wistar rats. British Journal of Nutrition, 119, 30-41.

Bayne, K. (1996). Revised guide for the care and use of laboratory animals available. American Physiological Society. The Physiologist, 39(199), 208-211.

Chen, P., Zhang, Q., Dang, H., Liu, X., Tian, F., Zhao, J., \& Chen, W. (2014a). Antidiabetic effect of Lactobacillus casei CCFM0412 on mice with type 2 diabetes induced by a high-fat diet and streptozotocin. Nutrition, 30, 1061-1068.

Chen, P., Zhang, Q., Dang, H., Liu, X., Tian, F., Zhao, J., \& Chen, W. (2014b). Screening for potential new probiotic based on probiotic properties and $\alpha$-glucosidase inhibitory activity. Food Control, 35, 65-72.

Chomczynski, P., \& Sacchi, N. (1987). Single-step method of RNA isolation by acid guanidinium thiocyanate-phenol-chloroform extraction. Analytical Biochemistry, 162, $156-159$.

Costa, W. K. A., Souza, G. T., Brandão, L. R., Lima, R. C., Garcia, E. F., Lima, M. S., .. Magnani, M. (2018). Exploiting antagonistic activity of fruit-derived Lactobacillus to control pathogenic bacteria in fresh cheese and chiken meat. Food Research International, 108, 172-182.

Daniel, C., Poiret, S., Goudercourt, D., Dennin, V., Leyer, G., \& Pot, B. (2006). Selecting lactic acid bacteria for their safety and functionality by use of a mouse colitis model. Applied Environmental Microbiology, 72, 5799-5805.

Delgado, G. T. C., Tamashiro, W. M. S. C., \& Pastore, G. M. (2010). Immunomodulatory effects of fructans. Food Research International, 43, 1231-1236.

Erben, U., Loddenkemper, C., Doerfel, K., Spieckermann, S., Haller, D., Heimesaat, M. M., ... Kühl, A. A. (2014). A guide to histomorphological evaluation of intestinal inflammation in mouse models. International Journal of Clinical and Experimental Pathology, 7, 4557-4576.

Erkosar, B., Storelli, G., Mitchell, M., Bozonnet, L., Bozonnet, N., \& Leulier, F. (2015). Pathogen virulence impedes mutualist-mediated enhancement of host juvenile growth via inhibition of protein digestion. Ceel Host \& Microbe, 18, 445-455.

FAO/WHO - Food and Agriculture Organization of United States/World Health Organization (2006). Probiotics in food, health and nutritional properties and guidelines for evaluation. Rome: FAO Food and Nutritional Paper.

Garcia, E. F., Luciano, W., Xavier, D., Costa, W. K. A., Oliveira, K., Franco, O., ... Souza, E. (2016). Identification of lactic acid bacteria in fruit pulp processing byproducts and potential probiotic properties of selected Lactobacillus strains. Frontiers in Microbiology, 30, 7-1371.

Grundy, S. M., Arai, H., Barter, P., Bersot, T. P., Betteridge, D. J., Carmena, R., ... Zhao, D. (2014). An International Atherosclerosis Society position paper: Global recommendations for the management of dyslipidemia - Full report. Journal of Clinical Lipidology, 8, 29-60.

Herigstad, B., Hamilton, M., \& Heersink, J. (2001). How to optimize the drop plate method for enumerating bacteria. Journal of Microbiological Methods, 44, 121-129.

Karasu, M., Simsek, O., \& Con, A. (2010). Technological and probiotic characteristics of 
Lactobacillus plantarum strains isolated from traditionally produced fermented vegetables. Annals of Microbiology, 60, 227-234.

Kearse, M., Moir, R., Wilson, A., Stones-Havas, S., Cheung, M., Sturrock, S., ... Drummond, A. (2012). Geneious basic: An integrated and extendable desktop software platform for the organization and analysis of sequence data. Bioinformatics, 28(12), 1647-1649.

Kechagia, M., Basoulis, D., Konstantopoulou, S., Dimitriadi, D., Gyftopoulou, K., Skarmoutsou, N., \& Fakiri, E. M. (2013). Health benefits of probiotics: A review. International Scolarly Research Notices Nutrition481651. (7 pages) https://doi.org/10. 5402/2013/481651.

Kim, B., Park, K. Y., Ji, Y., Park, S., Holzapfel, W., \& Hyun, C. K. (2016). Protective effects of Lactobacillus rhamnosus GG against dyslipidemia in high-fat diet-induced obese mice. Biochemical and Biophysical Research Communications, 473, 530-536.

Kim, E., Park, Y. M., Lee, O. Y., \& Lee, W. (2013). Draft genome sequence of Lactobacillus plantarum strain WJL, a Drosophila gut symbiont. Genome Announcements, 1. https:// doi.org/10.1128/genomeA.00937-13.

Kim, T. O., Hong, J., Choi, M. R., \& Kim, E. J. (2014). Effect of mixture of Lactobacillus plantarum CECT 7527, 7528, and 7529 on obesity and lipid metabolism in rats fed a high-fat diet. Journal of the Korean Society of Food Science and Nutrition, 94, 803-809.

Li, X., Wang, N., Yin, B., Fang, D., Jiang, T., Fang, S., ... Chen, W. (2016a). Effects of Lactobacillus plantarum CCFM0236 on hyperglycemia and insulin resistance in highfat and treptozotocin induced Type 2 diabetic mice. Journal of Applied Microbiology, $121,1727-1736$.

Li, X., Wang, N., Yin, B., Fang, D., Zhao, J., Zhang, H., ... Chen, W. (2016b). Lactobacillus plantarum X1 with $\alpha$-glucosidase inhibitory activity ameliorates Type 2 diabetes in mice. Royal Society of Chemistry Advances, 68.

Lien, E. L., Boyle, F. G., Wrenn, J. M., Perry, R. W., Thompson, C. A., \& Borzelleca, J. F. (2001). Comparison of AIN- 76A and AIN-3G dies: A 1-week study in rats. Food and Chermical Toxicology, 39, 385-392.

Matos, R. C., \& Leulier, F. (2014). Lactobacilli-host mutualism: Learning on the fly. Microbial Cell Factories, 13(Suppl. 1), S6.

Messias, G. C., Rocha, A. M. N., Santos, B. M. S., Botelho, A. M., Silva, D. C. A., Porto, E. S., ... Yatsuda, R. (2018). Administration of Lactobacillus plantarum Lp62 to dam rats at the end of delivery and during lactation affects TGF- $\beta 1$ level and nutritional milk composition, and body weight of pups. European Journal of Nutrition. https://doi.org/ 10.1007/s00394-018-1628-y.

Novelli, E., Diniz, Y., Galhardi, C., Ebaid, G. M., Rodrigues, H. G., Mani, F., ... Novelli Filho, J. L. (2007). Anthropometrical parameters and markers of obesity in rats. Laboratory Animals, 41, 111-119.

Park, S., Ji, Y., Jung, H. Y., Park, H., Kang, J., Choi, S. H., ... Holzapfel, W. H. (2017) Lactobacillus plantarum HAC01 regulates gut microbiota and adipose tissue accumulation in a diet-induced obesity murine model. Applied Microbiology and Biotechnology, 104, 1605-1614.
Reeves, P. G., Nielsen, F. H., \& Fahey, G. C. (1993). AIN 93 purified diets for laboratory rodents: Final report of the American Institute of Nutrition ad hoc writing committee on the reformulation of the AIN 76A rodent diet. Journal of Nutrition, 123, 1939-1951.

Rigo, R. S., Carvalho, C. M. E., Honer, M. R., Andrade, G. B., Silva, I. S., Rigo, L., ... Barreto, W. T. G. (2013). Renal histopathological findings in dogs with visceral leihhmaniasis. Journal of the São Paulo Institute of Tropical Medicine, 55, 113-116.

Salvetti, E., Torriani, S., \& Felis, G. E. (2012). The genus Lactobacillus: A taxonomic update. Probiotics and Antimicroal Proteins, 4, 217-226.

Sanders, M. E., Akkermans, L. M. A., Haller, D., Hammerman, C., Heimbach, J., Hörmannsperger, G., ... Vaughan, E. (2010). Safety assessment of probiotics for human use. Gut Microbes, 1, 164-185.

Schwarzer, M., Makki, K., Storelli, G., Machuca-Gayet, I., Strutkova, D., Hermanova, P., ... Leulier, F. (2016). Lactobacillus plantarum strain maintains growth of infant mice during chronic undernutrition. Science, 51, 854-857.

Shanahan, F. (2012). A commentary on the safety of probiotics. Gastroenterology Clinics of North America, 41, 869-876.

Siezen, R. J., \& Vlieg, J. E. H. (2011). Genomic diversity of Lactobacillus plantarum, a natural metabolic engineer. Microbial Cell Factories, 10. https://doi.org/10.1186/ 1475-2859-10-S1-S3.

Storelli, G., Defaye, A., Erkosar, B., Hols, P., Royet, J., \& Leulier, F. (2011). Lactobacillus plantarum promotes Drosophila systemic growth by modulating hormonal signals through TOR-dependent nutrient sensing. Cell Metabolism, 14, 403-414.

Tuohy, K. M., Pinart-Gilberga, M., Jones, M., Hoyles, L., Mccartney, A. L., \& Gibson, G. R. (2007). Survivability of a probiotic Lactobacillus casei in the gastrointestinal tract of healthy human volunteers and its impact on the faecal microflora. Journal of Applied Microbiology, 102, 1026-1032.

Untergrasser, A., Cutcutache, I., Koressaar, T., Ye, J., Faircloth, B. C., Remm, M., \& Rozen, S. G. (2012). Primer3 - New capabilities and interfaces. Nucleic Acids Research, 40, e115.

Vitali, B., Minervini, G., Rizzello, C. G., Spisni, E., Maccaferri, S., Brigidi, P., ... Di Cagno, R. (2012). Novel probiotic candidates for humans isolated from raw fruits and vegetables. Food Microbiology, 31, 116-125.

Wang, B., Li, J., Li, Q., Zhang, H., \& Li, N. (2009). Isolation of adhesive strains and evaluation of the colonization and immune response by Lactobacillus plantarum L2 in the rat gastrointestinal tract. International Journal of Food Microbiology, 132, 59-66.

Wang, R., Chen, S., Jin, J., Ren, F., Li, Y., Qiao, Z., ... Zhao, L. (2015). Survival of Lactobacillus casei strain Shirota in the intestines of healthy Chinese adults. Microbiology and Immunology, 59, 268-276.

Wang, X., Xu, N., Xi, A., Ahmed, Z., Zhang, B., \& Bai, X. (2009). Effect of Lactobacillus plantarum MD2 isolated from Tibet kefir on lipid metabolism and intestinal microflora of rats fed on high-cholesterol diet. Applied Microbial and Cell Physiology, 84, 341-347. 